\title{
A expansão dos colégios militares no Rio de Janeiro: uma análise sob a perspectiva constitucional
}

\author{
The expansion of military schools in Rio de Janeiro: \\ an analysis from the constitutional perspective \\ La ampliación de las escuelas militares en Río de Janeiro: \\ un análisis desde la perspectiva constitucional
}

\author{
ROGÉRIO PACHECO ALVES \\ https://orcid.org/0000-0003-0531-8950 \\ Universidade Federal Fluminense \\ Programa de Pós-graduação em Direito \\ Faculdade de Direito \\ Niterói, RJ, Brasil \\ DEBORA DA SILVA VICENTE \\ https://orcid.org/0000-0002-1675-1592 \\ Universidade Federal Fluminense \\ Programa de Pós-graduação em Educação \\ Faculdade de Educação \\ Niterói, RJ, Brasil
}

\begin{abstract}
Resumo: A criação de colégios militares no Brasil, a partir do Segundo Império, subsiste e ganhou força nos Estados da Federação. O presente trabalho pretende analisar o processo de expansão dos colégios militares no Rio de Janeiro, na perspectiva da Carta Política de 1988, em especial sob o prisma da supremacia da norma constitucional, dos princípios setoriais da educação e da igualdade. A metodologia, de abordagem qualitativa, consistirá na revisão bibliográfica sobre o tema e como resultado apresenta-se uma discussão sobre a incompatibilidade da militarização da educação com o regime democrático.
\end{abstract}

Palavras-chave: Educação. Ensino Militar. Princípios Constitucionais. Democracia

\begin{abstract}
The creation of the first Military College, from the end of the Second Empire, continues and gained strength in the States of the Federation. The present work intends to analyze the expansion process of the military colleges in Rio de Janeiro, in the perspective of the 1988 Constitution, especially under the prism of the supremacy of the constitutional norm, of the sectorial principles of education and equality. The methodology, with a qualitative approach, will consist of a bibliographic review on the theme and as a result a discussion is presented about the incompatibility of the militarization of education with the democratic regime.
\end{abstract}

Keywords: Education. Military Education. Constitutional principles. Democracy

Rev. Bras. Polít. Adm. Educ. - v. 37, n. 3, p. 1441 - 1462, set./dez. 2021 • 1441 
Resumen: La creación de colegios militares en Brasil, a partir del Segundo Imperio, permanece y cobró fuerza en los Estados de la Federación. El presente trabajo pretende analizar el proceso de expansión de los colegios militares en Río de Janeiro, en la perspectiva de la Carta Politica de 1988, especialmente bajo el prisma de la supremacía de la norma constitucional, de los principios sectoriales de educación e igualdad. La metodología, con un enfoque cualitativo, consistirá en una revisión bibliográfica sobre el tema y como resultado se presenta una discusión sobre la incompatibilidad de la militarización de la educación con el régimen democrático.

Palabras clave: Educación. Educación militar. Principios constitucionales. Democracia

\section{INTRODUÇÃO}

Atingido por intensa crise fiscal que resultou em inédita decretação de calamidade financeira e na adesão ao Regime de Recuperação Fiscal instituído pela Lei Complementar Federal 159/2017, o Estado do Rio de Janeiro tem se notabilizado por suas dificuldades em garantir acesso universal, com equidade e qualidade, à sua rede de ensino, bem como pelo uso constante do argumento da escassez orçamentária para justificar o descumprimento de suas obrigações em matéria educacional, o que foi, inclusive, publicamente reconhecido em mais de uma oportunidade. ${ }^{1}$

Em sentido diametralmente oposto e de forma contraditória, no entanto, durante os anos de 2018 e 2019 o Estado do Rio de Janeiro colocou em prática, por meio dos seus Poderes Legislativo e Executivo, e até mesmo por ação do Interventor Federal (2018), uma série de ações destinadas à ampliação do número de seus colégios militares, sem aludir a qualquer tipo de escassez de recursos.

Os municípios e localidades onde instalados os novos colégios militares estaduais carecem, de um modo geral, de oferta de vagas em número suficiente ao atendimento da demanda por atendimento escolar pela população em geral e, por essa razão, deve chamar a atenção tanto a opção administrativa pelo atendimento preferencial, se não exclusivo, de público específico e determinado, em detrimento de todos os demais cidadãos, quanto a delegação, à Polícia Militar (PMERJ) e ao Corpo de Bombeiros Militar do Estado do Rio de Janeiro (CBMERJ), do exercício de atribuições que lhe são constitucionalmente estranhas. Tais iniciativas já são objeto de questionamento judicial ${ }^{2}{ }^{3}$, em que são apontadas violações

\footnotetext{
1 Veja, por exemplo, entrevista do Secretário Estadual de Educação em https://cbn.globoradio.globo. $\mathrm{com} / \mathrm{media} /$ audio/239682/secretario-de-educacao-admite-falta-de-vagas-em-es.htm

2 Ação Civil Pública n ${ }^{\circ}$ 5006378-31.2018.4.02.5118/RJ, em tramitação na $1^{\text {a }}$ Vara Federal de Duque de Caxias, proposta pelo MPRJ e pelo MPF.

3 Ação Civil Pública no 0036330-90.2020.8.19.0001, em tramitação na $1^{\text {a }}$ Vara da Infância, da Juventude e do Idoso da Comarca da Capital, proposta pelo MPRJ.
} 
diversas ao texto constitucional, merecendo destaque, neste artigo, as discussões relativas à necessidade de observância da supremacia da norma constitucional, dos princípios setoriais da educação e da igualdade.

Como questão de fundo, as críticas ao modelo de educação militar estão ancoradas em aspectos muito caros à democracia e ao seu enfraquecimento por força de um processo contínuo de militarização da vida e das práticas sociais, do que são exemplos recentes as iniciativas de facilitação do acesso de armas pela população e também a ampliação da doutrinação militar como estratégia de controle social. Tais problemas aparecem de forma muito clara no Programa Nacional das Escolas Cívico-Militares, instituído pelo Decreto n. 10.004/19, que tem como objetivo declarado a inserção de oficiais e praças das polícias militares e dos corpos de bombeiros militares para atuarem nas áreas de gestão educacional, didático-pedagógica e administrativa, muito embora a finalidade formalmente alegada seja a melhoria da educação através de um programa de "excelência pedagógica". Trata-se de uma importante estratégia do atual Estado brasileiro, que vem crescendo mesmo durante o momento adverso da Pandemia causada pela COVID. ${ }^{4}$

O presente trabalho pretende analisar o processo de expansão dos colégios militares no Estado do Rio de Janeiro, na perspectiva da Constituição Federal de 1988, em especial sob o prisma da observância da supremacia da norma constitucional, dos princípios setoriais da educação e da igualdade. A metodologia adota, de abordagem qualitativa, consistirá na revisão bibliográfica sobre o tema, com incursões nos campos do direito educacional e do direito constitucional. Como resultado apresenta-se uma discussão sobre a compatibilidade da ampliação dos Colégios Militares no Rio de Janeiro com o regime democrático e com o acesso igualitário à educação.

\section{O ENSINO MILITAR E OS COLÉGIOS MILITARES NO BRASIL}

O ensino militar no Brasil encontra previsão no art. 83 da Lei Federal 9394/1996 (Lei de Diretrizes e Bases da Educação Nacional), que exige regulamentação "em lei específica, admitida a equivalência de estudos, de acordo com as normas fixadas pelos sistemas de ensino" e tem por finalidade precípua a de promover a preparação ou formação de quadros especializados para o exercício das funções próprias dos cargos públicos que compõem a estrutura organizacional das Forças Armadas (Marinha, Exército e Aeronáutica). Assim, suas unidades de ensino, consideradas organizações militares, dedicam-se ao

4 Governo Federal implantou 51 escolas cívico- militares durante a pandemia: https://www. gazetadopovo.com.br/educacao/governo-escolas-civico-militares-pandemia, acesso em 24.02.21. 
atendimento educacional em diferentes níveis e modalidades de ensino, desde o ensino superior, destinado à formação de oficiais, até a educação técnicoprofissional, destinada à formação de sargentos.

No entanto, dentre as unidades de ensino militar figura, ainda, um conjunto delas, denominadas Colégios Militares, cuja finalidade não se relaciona à necessidade de formação de recursos humanos para o exercício de funções dos cargos próprios das Forças Armadas, mas ao papel de garantir assistência ou amparo educacional aos dependentes de seus integrantes, ao longo de todas ou de algumas das etapas da educação básica.

Os Colégios Militares foram concebidos em nosso país ao final do século XIX com o objetivo de acolher os órfãos de guerra, inicialmente os da Guerra do Paraguai (1864/1870), bem como o de garantir a educação dos filhos dos militares das forças armadas, em razão das constantes transferências, por todo o território nacional e também em missões fora do País, a que estão submetidos tais agentes públicos. ${ }^{5}$

Datam do Período Regencial as primeiras tentativas de criação de um colégio militar destinado a educar os filhos dos servidores do Exército e da Armada. Dentre os seus defensores figuraram personalidades como Araújo Filho, Duque de Caxias e Tomás Coelho. No entanto, apenas ao final do Segundo Império foi aprovada a criação do Imperial Colégio Militar, ${ }^{6}$ por força do Decreto n. 10.202, de 9 de março de 1889, posteriormente denominado Colégio Militar do Rio de Janeiro.

Em 1912 foram criados os Colégios Militares de Porto Alegre e Barbacena, extintos, respectivamente, em 1925 e 1938. Criado em 1919, o Colégio Militar de Fortaleza também foi extinto em 1938. Entre os anos de 1955 e 1959 foram criados os Colégios Militares de Belo Horizonte, Salvador, Curitiba e Recife, todos fechados em 1988 e reabertos em $1993 .^{7}$

Os antigos Colégios Militares de Porto Alegre e de Fortaleza voltaram a funcionar em 1962 e durante o regime civil-militar o modelo foi ampliado, criando-se os Colégios Militares de Manaus (1971) e de Brasília (1978). ${ }^{8}$

5 Fonte: http://www.depa.eb.mil.br/historico, acessado em 24.02.21.

6 Idem.

7 Idem.

$8 \quad$ Idem. 
Somente em 1989 e, portanto, após a promulgação da Constituição Federal de 1988, as mulheres foram admitidas como alunas de tais instituições militares, e em 1993 foram criados os Colégios Militares de Juiz de Fora e de Campo Grande; em 1994, o de Santa Maria e em 2018, o Colégio Militar de São Paulo, $14^{\circ}$ Colégio Militar do Brasil. ${ }^{?}$

Os Colégios Militares são, sem sombra de dúvidas, instituições públicas de ensino (art. 19 da LDB) e, como tal, a sua existência e funcionamento devem encontrar fundamento nos preceitos constitucionais e nas normas gerais da LDB.

A Lei Federal n. 9.786/1999 instituiu o Sistema de Ensino do Exército, regulamentado pelo Decreto Federal n. 3.182/1999, com alterações introduzidas pelo Decreto Federal n. 9.171/2017, orientado por princípios ${ }^{10}$ e modalidades ${ }^{11}$ de ensino próprios e destinado a "qualificar recursos humanos para a ocupação de cargos e para o desempenho de funções previstas, na paz e na guerra, em sua organização" (art. $1^{\circ}$ ). A legislação em questão é expressa, ainda, em apontar que o ensino preparatório e assistencial de nível fundamental e médio, de que são unidades os Colégios Militares, constitui modalidade de ensino adicional às propriamente militares $\left(\operatorname{art.} 7^{\circ}\right)$.

Os Colégios Militares do Exército se submetem, ainda, ao Regulamento dos Colégios Militares aprovado pela Portaria n. 42/2008, expedida pelo Comandante do Exército, segundo o qual se destinam ao atendimento educacional

$9 \quad$ Idem.

$10 \quad$ Art. $3^{\circ}$ da Lei Federal n. 9.786/99: "O Sistema de Ensino do Exército fundamenta-se, basicamente, nos seguintes princípios: I - integração à educação nacional; II - seleção pelo mérito; III - profissionalização continuada e progressiva; IV - avaliação integral, contínua e cumulativa; V - pluralismo pedagógico; VI - aperfeiçoamento constante dos padrões éticos, morais, culturais e de eficiência; VII - titulações e graus universitários próprios ou equivalentes às de outros sistemas de ensino.

11 "Art. $6^{\circ}$ Para atender a sua finalidade, o Sistema de Ensino do Exército mantém as seguintes modalidades de cursos:

I - formação, que assegura a qualificação inicial, básica para a ocupação de cargos e para o desempenho de funções de menor complexidade em cada segmento da carreira militar, e a prestação do serviço militar inicial e suas prorrogações;

II - graduação, que qualifica em profissões de nível superior, com ou sem correspondentes civis, para a ocupação de cargos e para o desempenho de funções militares;

III - especialização, que qualifica para a ocupação de cargos e para o desempenho de funções que exijam conhecimentos e práticas especializadas;

IV - extensão, que amplia os conhecimentos e as técnicas adquiridos em cursos anteriores, necessários para a ocupação de determinados cargos e para o desempenho de determinadas funções;

V - aperfeiçoamento, que atualiza e amplia conhecimentos obtidos com a formação ou a graduação, necessários para a ocupação de cargos e para o desempenho de funções de maior complexidade;

VI - altos estudos militares, que qualifica para a ocupação de cargos e para o desempenho de funções privativos do Quadro de Estado-Maior da Ativa, bem como atualiza, amplia e estrutura conhecimentos em ciências militares, políticas e sociais;

VII - preparação, que amplia, sedimenta e uniformiza conhecimentos, bem como qualifica para o ingresso em determinados cursos". 
de dependentes de militares de carreira do Exército e aos habilitados em processo seletivo nos anos finais do ensino fundamental e no ensino médio, bem como ao Regimento Interno dos Colégios Militares.

Atualmente 14 Colégios Militares compõem o Sistema Colégio Militar do Brasil (SCMB), um dos subsistemas do Sistema de Ensino do Exército sob o controle da Diretoria de Educação Preparatória e Assistencial, subordinada, por sua vez, ao Departamento de Educação e Cultura do Exército (DECEX).

Desse rápido retrospecto histórico percebe-se que a experiência da educação militar no Brasil encontra-se já consolidada e que a sua criação visava a atender a situações de interesse público relacionadas ora à formação dos quadros de pessoal das próprias Forças Armadas, ora a questões relacionadas à movimentação territorial dos militares (transferências), por razões administrativas peculiares ao exercício das carreiras militares.

\section{OS COLÉGIOS MILITARES NO RIO DE JANEIRO}

No Estado do Rio de Janeiro, embora sem previsão expressa na Lei Estadual n. 4528/2005, que estabelece as diretrizes para a organização do Sistema Estadual de Ensino, a criação de Colégios da Polícia Militar do Estado do Rio de Janeiro (CPMERJ) tem previsão na Lei Estadual n. 3751/2002, com alterações introduzidas pela Lei Estadual n. 6343/2012, e se destina ao atendimento escolar de servidores da corporação e dos seus dependentes, desde o segundo segmento do ensino fundamental até o ensino médio, assegurando-se o ingresso após aprovação em processo seletivo e admitindo-se o atendimento de outros interessados no caso de ociosidade de vagas. O primeiro colégio da Polícia Militar fluminense (I CPMERJ) foi criado pelo Decreto Estadual n. 38.731/2006 e instalado na cidade de Niterói, no ano de 2002.

A Lei Estadual n. 8198/2018 autorizou o Poder Executivo a criar outras três novas unidades do Colégio da Polícia Militar, localizadas na Baixada Fluminense, na Zona Norte e na Zona Oeste da Capital. Naquele mesmo ano o II CPMERJ foi criado pela Resolução SESEG n. 1.211/2018 e instalado no bairro de Campo Grande, cidade do Rio de Janeiro, enquanto o III CPMERJ foi criado por ato do Interventor Federal, ${ }^{12}$ consubstanciado no Decreto do Interventor n. 22/2018, posteriormente ratificado por ato conjunto do Governador e do Interventor (Decreto Conjunto n. 02/2018), e instalado na cidade de Duque de Caxias (Colégio Militar Percy Geraldo Bolsonaro).

12 Decreto Federal 9.288, de 16 de fevereiro de 2018, decreta Intervenção Federal no Estado do Rio de Janeiro. 
A Lei Estadual n. 8450/2019 autorizou o Poder Executivo a implantar um quinto colégio militar na estrutura da PMERJ, a ser localizado no município de Queimados, em relação ao qual, no entanto, assim como em relação ao CPMERJ a ser criado na Zona Oeste do município do Rio de Janeiro, não foram adotadas as medidas necessárias para sua instalação.

Os colégios da PMERJ são organizações da Polícia Militar (OPM) do Estado do Rio de Janeiro e integram a estrutura da Diretoria de Ensino e Instrução (DEI), órgão de Direção Setorial incumbido do planejamento, coordenação, fiscalização e controle das atividades do Sistema de Ensino e Instrução da Polícia Militar do Estado do Rio de Janeiro (PMERJ), cujo regulamento remonta ao Decreto Estadual n. 15.427/1990.

Por sua vez, a criação de colégios do Corpo de Bombeiros Militar do Estado do Rio de Janeiro (CCBM) tem previsão na Lei Estadual n. 4.133/2003, sendo certo que apenas no ano de 2019, por meio do Decreto Estadual n. 46.592/19 foram criados e instalados os I e II CCBM, respectivamente, nas cidades de Volta Redonda e Miguel Pereira. Os colégios do Corpo de Bombeiros Militar também se destinam ao atendimento escolar de servidores da corporação e dos seus dependentes, limitando-se, entretanto, à oferta de matrículas na etapa do ensino médio. Assim como nos colégios da Polícia Militar, o ingresso se dá por meio de aprovação em processo seletivo admitindo-se o atendimento de outros interessados no caso de existência de vagas ociosas.

A instalação de dois colégios do Corpo de Bombeiros Militar do Estado do Rio de Janeiro, ainda no ano de 2019, cumpriu compromisso assumido pelo Governador eleito e expresso no "Plano de Diretrizes Prioritárias do Governo do Estado do Rio de Janeiro - 2019/2022", por meio do qual foram estabelecidas as metas para os primeiros dias do governo. ${ }^{13}$

Os colégios do CCBM são organizações do Corpo de Bombeiros Militar $(\mathrm{OBM})$ e estão subordinados à Diretoria-Geral de Ensino e Instrução (DGEI), órgão de Direção Setorial que tem por missão planejar, dirigir, orientar, coordenar, fiscalizar e controlar as atividades de ensino e instrução, de seleção interna e de pesquisa do Sistema de Ensino de Bombeiros Militar (SEBM) e encontra regulamento na Portaria n. 608/2010, expedida pelo Comando-Geral.

O tema despertou tanto o interesse dos Deputados Estaduais do Rio de Janeiro que nada menos do que vinte e oito Projetos de Lei foram apresentados no ano de 2019, ${ }^{14}$ visando à concessão de autorização legislativa para a criação de novos colégios militares nas estruturas da Polícia Militar e do Corpo de Bombeiros

13 Disponível em https://casafluminense.org.br/wp-content/uploads/2019/05/Plano-de-Diretrizese-Iniciativas-Prioritárias-do-Governo.pdf 
Militar. Os Projetos de Lei em questão têm como autores treze dentre os setenta Deputados Estaduais, e buscam a instalação dessas unidades públicas de ensino em vinte e dois municípios diferentes dentre os noventa e dois existentes no Estado do Rio de Janeiro.

Um dado a ser destacado é que durante as legislaturas exercidas entre os anos de 2002 e 2018 tramitaram apenas quatro Projetos de Lei, na ALERJ, com o mesmo objeto, sendo três deles aprovados. ${ }^{15} \mathrm{O}$ aumento significativo de propostas legislativas com o objetivo de ampliar os colégios militares no Rio de Janeiro parece justificado pelo episódico, e posteriormente desfeito, alinhamento político do Estado do Rio de Janeiro ao Governo Federal, que, como visto, criou o Programa Nacional das Escolas Cívico-Militares em 2019.

O ano de 2019 também testemunhou a apresentação de nada menos que oitenta Indicações Legislativas destinadas a solicitar ao Governo do Estado o envio de mensagem para criação de novos colégios militares em municípios de todas as regiões. ${ }^{16}$ As Indicações Legislativas em questão têm como autores dez Deputados Estaduais e buscam a instalação dessas unidades públicas de ensino em vinte e nove municípios fluminenses.

De um modo geral, tais Projetos de Lei e Indicações Legislativas apresentam como justificativa para a expansão dos colégios militares a reconhecida qualidade do serviço educacional ofertado pelo I CPMERJ, traduzido nos indicadores de resultados obtidos, em especial pelo IDEB, frequentemente maiores que a média do IDEB das unidades das redes públicas de ensino no Estado do Rio de Janeiro, bem como pela possibilidade de assegurar maior segurança aos alunos, famílias e comunidades atendidas.

Merecem destaque, ainda, sobretudo em razão de sua extensão e possíveis impactos, outros dois Projetos de Lei destinados à criação de colégios militares no Estado do Rio de Janeiro: o Projeto de Lei n. 862/2019, que autoriza o Estado a celebrar convênios com os municípios para a criação de escolas militares municipais; e o Projeto de Lei n. 192/2019, que autoriza a criação de colégios militares por transformação das unidades escolares estaduais atualmente localizadas em todas as comunidades do território fluminense. Ambos os Projetos de Lei demandam considerações próprias sobre a sua constitucionalidade, as quais, entretanto, não serão foco do presente trabalho, sendo contudo importante

$\begin{array}{ll}15 & \text { Idem. } \\ 16 & \text { Idem. }\end{array}$


notar que os movimentos legislativos e administrativos, na linha do Programa Nacional das Escolas Cívico-Militares, apontam que a militarização da educação no Estado do Rio de Janeiro representa uma coalizão política entre o Executivo e o Legislativo estaduais.

\section{OS COLÉGIOS MILITARES DA PMERJ E DO CBMERJ E A SUPREMACIA DA CONSTITUIÇÃO}

Embora historicamente consolidado no campo educacional, o exercício de atividades de educação básica pelas Forças Armadas pode ser classificado como anômalo e excepcional, tendo em vista que tais instituições nacionais se destinam à defesa da Pátria, à garantia dos poderes constitucionais e da lei e da ordem (art. 142 da Constituição Federal).

Já o art. 144 da Constituição Federal, ao prever as funções e atribuições dos órgãos de segurança pública, dentre eles as polícias militares e corpos de bombeiros militares estaduais, estabelece o seguinte:

\footnotetext{
"Art. 144. A segurança pública, dever do Estado, direito e responsabilidade de todos, é exercida para a preservação da ordem pública e da incolumidade das pessoas e do patrimônio, através dos seguintes órgãos:

I - polícia federal;

II - polícia rodoviária federal;

III - polícia ferroviária federal;

IV - polícias civis;

$\mathrm{V}$ - polícias militares e corpos de Bombeiros Militar .

VI - polícias penais federal, estaduais e distrital (Redação dada pela Emenda Constitucional 104, de 2019).

(...)

$\int 5^{\circ}$ Às polícias militares cabem a polícia ostensiva e a preservação da ordem pública; aos corpos de Bombeiros Militar, além das atribuições definidas em lei, incumbe a execução de atividades de defesa civil.

(...)

$\int 6^{\circ}$ As polícias militares e os corpos de Bombeiros Militar, forças auxiliares e reserva do Exército subordinam-se, juntamente com as polícias civis e as polícias penais estaduais e distrital, aos Governadores dos Estados, do Distrito Federal e dos Territórios.

(...)" - grifamos.
}

No caso específico do Rio de Janeiro, a Constituição Estadual também prevê caber à Polícia Militar "a polícia ostensiva e a preservação da ordem pública" e ao Corpo de Bombeiros Militar "a execução de atividades de defesa civil" (art. 189), parecendo bastante claro, então, que a legislação estadual que permite que a Polícia Militar e que o Corpo de Bombeiro Militar prestem atendimento 
educacional na educação básica (no ensino fundamental, a partir do $6^{\circ}$ ano, e no ensino médio), se afasta da Constituição Federal de 1988 e também da própria Constituição do Estado do Rio de Janeiro, que estabelecem, de forma exaustiva, as funções e as atribuições da Polícia Militar e do Corpo de Bombeiros Militar do Estado do Rio de Janeiro.

Feitas as devidas adaptações, foi o que o Supremo Tribunal Federal decidiu ao declarar parcialmente inconstitucional o art. 183 da Constituição do Estado do Rio de Janeiro, que incluía a "vigilância intramuros nos estabelecimentos penais" no conceito de segurança pública. ${ }^{17} \mathrm{Na}$ ocasião ficou registrado no voto do relator, a partir do previsto no art. 25 da Constituição Federal, ${ }^{18}$ que os Estados não podem alterar ou acrescer as competências das polícias militares, corpos de bombeiros militares e polícias civis dos Estados, em razão dos limites já impostos pela Constituição Federal. ${ }^{19}$

Assim, da mesma forma que não cabe aos Estados, sequer em suas Constituições, ampliar o conceito de segurança pública, também não cabe a eles, através de meras leis estaduais, alargar as funções e atribuições que a Constituição Federal estabelece para a polícia militar e para o corpo de bombeiros militar, responsáveis, repita-se, pela polícia ostensiva, a preservação da ordem pública e a execução de atividades de defesa civil, não pela prestação de serviços educacionais (XIMENES, STUCHI, MOREIRA, 2019). O texto constitucional, neste passo, limita o atuar legislativo e administrativo dos Estados e o faz de modo bastante razoável na medida em que as capacidades institucionais dos órgãos de segurança pública, ou seja, suas habilidades específicas, limitações, recursos e condições administrativas (ARGUELHES \& LEAL, 2011), a partir do desenho constitucional de 1988, se restringem à preservação da ordem pública e da incolumidade das pessoas e do patrimônio e, no caso específico do Corpo de Bombeiros, também à execução de atividades de defesa civil. Não há, aqui, qualquer espaço para uma "concorrência harmônica" entre as forças de segurança pública e as instituições de ensino das unidades federativas (União, Estados e Municípios).

Aqui cabe um breve parêntese: No âmbito da Administração Pública o exercício das funções e atribuições encontra-se regido pelo Princípio da Legalidade (art. 37 da Constituição Federal), o que significa que aos agentes

17 “Art. 183 - A segurança pública, que inclui a vigilância intramuros nos estabelecimentos penais, dever do Estado, direito e responsabilidade de todos, é exercida para a preservação da ordem pública e da incolumidade das pessoas e do patrimônio, pelos seguintes órgãos estaduais".

18 "Art. 25. Os Estados organizam-se e regem-se pelas Constituições e leis que adotarem, observados os princípios desta Constituição.

$\llbracket 1^{\circ}$ São reservadas aos Estados as competências que não lhes sejam vedadas por esta Constituição. (...)". 
públicos e às instituições públicas só é autorizado fazer aquilo que a regra de competência estabelece categoricamente, aquilo que a lei (no caso, o próprio texto constitucional) delimita de forma bastante clara aos órgãos estaduais de segurança pública. Ou seja, no regime de direito público não é competente quem quer, mas quem pode, segundo a norma constitucional (TÁCITO, 1997), o que afasta a possibilidade de voluntarismos "bem intencionados" por parte do legislador.

Se é verdade que a eficácia de toda atividade administrativa está condicionada ao atendimento da Lei, não nos é permitido esquecer que esta mesma Lei deve encontrar o seu fundamento de validade na norma constitucional cujo atributo de supremacia na ordem jurídica invalida todas as demais normas que com ela não mantenham absoluta relação de compatibilidade vertical.

Aliás, de acordo com o art. 22, XXI, da Constituição Federal compete privativamente à União legislar sobre "normas gerais de organização, efetivos, material bélico, garantias, convocação, mobilização, inatividades e pensões das polícias militares e dos corpos de Bombeiros Militar", o que já seria suficiente a sustentar a inconstitucionalidade de leis estaduais que autorizem as polícias militares e os corpos de bombeiros militares a prestarem serviços educacionais, tal como se dá no Estado do Rio de Janeiro.

Especificamente sobre a hipótese do art. 22, XXI, é relevante notar que o texto Constitucional desejou atribuir à União competência legislativa privativa, diferentemente do que se verifica no art. 24, XVI, da mesma Carta Política, que permite aos Estados legislarem concorrentemente sobre "organização, garantias, direitos e deveres das polícias civis”. E a razão da distinção, no caso, é bastante clara, na medida em que as polícias militares e os corpos de bombeiros militares constituem "forças auxiliares e reserva do Exército" (art. 144, \ $6^{\circ}$ ), uma tema em que os Estados não podem ingressar por tratar-se de questão relativa à soberania nacional.

\section{OS COLÉGIOS MILITARES DA PMERJ E DO CBMERJ E OS PRINCÍPIOS SETORIAIS DA EDUCAÇÃO NACIONAL}

Seria o caso de também indagar se as leis estaduais que criam os colégios militares no Estado do Rio de Janeiro estariam de acordo com os arts. 22, XXIV, e 24, IX, da Constituição Federal, que cuidam das competências legislativas dos entes federativos em matéria de educação: 
“Art. 22. Compete privativamente à União legislar sobre:

(...)

XXIV - diretrizes e bases da educação nacional;

Art. 24. Compete à União, aos Estados e ao Distrito Federal legislar concorrentemente sobre:

(...)

IX - educação, cultura, ensino, desporto, ciência, tecnologia, pesquisa, desenvolvimento e inovação;

$\int 1^{\circ}$ No âmbito da legislação concorrente, a competência da União limitar-se-á a estabelecer normas gerais.

$\int 2^{\circ}$ A competência da União para legislar sobre normas gerais não exclui a competência suplementar dos Estados.

$\int 3^{\circ}$ Inexistindo lei federal sobre normas gerais, os Estados exercerão a competência legislativa plena, para atender a suas peculiaridades.

$\int 4^{\circ}$ A superveniência de lei federal sobre normas gerais suspende a eficácia da lei estadual, no que lhe for contrário."(grifamos)

A pergunta foi recentemente respondida pelo Supremo Tribunal Federal por ocasião da apreciação de medida cautelar formulada nos autos da Ação de Descumprimento de Preceito Fundamental n. 600/PR, em que se discutia a vedação ao ensino sobre gênero em escolas municipais:

“DIREITO À EDUCAÇÃO. MEDIDA CAUTELAR EM ARGUIÇÃO DE DESCUMPRIMENTO DE PRECEITO FUNDAMENTAL. LEI MUNICIPAL QUE VEDA O ENSINO SOBRE GÊNERO, BEM COMO A UTILIZAÇÃO DO CONCEITO NAS ESCOLAS. (...)

1.Violação à competência privativa da União para legislar sobre diretrizes e bases da educação nacional (CF/88, art. 22, XXIV), bem como à competência deste mesmo ente para estabelecer normas gerais em matéria de educação. Inobservância dos limites da competência normativa suplementar municipal (CF/88, art. 30, II).

2.Supressão de domínio do saber do universo escolar. Desrespeito ao direito à educação com o alcance pleno e emancipatório que lhe confere a Constituição. Dever do Estado de assegurar um ensino plural, que prepare os indivíduos para a vida em sociedade. Violação à liberdade de ensinar e de aprender (CF/88, art. 205; art. 206, II, III, V, e art. 214.

(...)

II. A COMPETÊNCIA LEGISLATIVA DA UNIÃO PARA DISPOR SOBRE EDUCAÇÃO (CF, ART. 22, XXIV, E ART. 24, IX).

10. De acordo com a Constituição de 1988, compete privativamente à União dispor sobre as diretrizes e bases da educação nacional (CF/88, art. 22, XXIV). Compete-lhe, ainda, estabelecer normas gerais sobre a matéria, a serem complementadas pelos Estados, no âmbito da sua competência normativa concorrente (CF/88, art. 24, IX). Cabe, por fim, aos Municípios suplementar as normas federais e estaduais $(\mathrm{CF} / 88$, art. 30, II). 
11. Como já tive a oportunidade de explicitar, legislar sobre as diretrizes da educação significa dispor sobre a orientação e sobre o direcionamento que devem conduzir as ações na matéria. Tratar das bases do ensino implica, por sua vez, prever os alicerces que servem de apoio à educação, os elementos que the dão sustentação e coesão. Ocorre que a Constituição estabelece expressamente como diretrizes para a organização da educação: $a$ promoção do pleno desenvolvimento da pessoa, do desenvolvimento bumanístico do país, do pluralismo de ideias, bem como da liberdade de ensinar e de aprender (CF/88, art. 205; art. 206, II e III; art. 214). Confira-se o teor dos pertinentes dispositivos:

(...)

12. A norma impugnada veda a adoção de política educacional que trate de gênero. Suprime, portanto, saber das salas de aula e do horizonte informacional de crianças e jovens, interferindo sobre as diretrizes, que, segundo a própria Constituição, devem orientar as ações em matéria de educação. Ao legislar em tais termos, o Município dispôs, portanto, sobre matéria objeto da competência privativa da União sobre a qual deveria se abster de atuar.

13. Além disso, estabeleceu norma que conflita com a Lei 9.394/1996 (Lei de Diretrizes de Bases da Educação), editada pela União, com base no exercício de tal competência privativa, e que prevê, além da garantia dos valores constitucionais acima elencados, o respeito à liberdade, o apreço à tolerância e a vinculação entre educação e práticas sociais como princípios que devem orientar as ações educacionais (arts. $2^{\circ}$ e $3^{\circ}$, II, III e IV). Veja-se o teor dessa última:

(...)

14. Desse modo, sequer seria possível defender que a norma atacada decorre apenas do exercício da competência normativa suplementar do Município de Londrina (CF/88, art. 30, II). Ainda que se viesse a admitir a possibilidade do exercício de competência suplementar na matéria, seu exercício jamais poderia ensejar a produção de norma antagônica às diretrizes constantes da Lei $9.394 / 1996$.

(...)

(ADPF/MC n. 600/PR, Rel. Min. Luís Roberto Barroso, j. 12.12.19 - grifamos)

O precedente aplica-se perfeitamente ao caso do Rio de Janeiro, tendo em vista que a legislação estadual que cria os colégios militares estaduais viola diversos princípios da educação nacional previstos tanto na Constituição Federal, quanto na LDB. De fato, sendo os Colégios da Polícia Militar e do Corpo de Bombeiros Militar do Estado do Rio de Janeiro verdadeiras "instituiçoes militares e forças auxiliares e reserva do Exército" a sua regência se dá pelos princípios da hierarquia e disciplina (art. 142 da Constituição Federal), os quais, no entanto, se chocam frontalmente com os princípios constitucionais da educação enquanto direito fundamental, mais especificamente com os princípios da "liberdade de aprender, 
ensinar, pesquisar e divulgar o pensamento, a arte e o saber", do "pluralismo de ideias e de concepções pedagógicas" e, fundamentalmente, o princípio da "gestão democrática" (art. 206, II, III, VI, da CF). ${ }^{20}$

$\mathrm{Na}$ LDB, tais princípios estão consagrados pelo art. $3^{\circ}$, II, III e VIII, e também pelo inciso IV do mesmo artigo, que fala em "respeito à liberdade e apreço à tolerância", e pelo art. 14, o qual estabelece que os sistemas de ensino definirão as normas da gestão democrática do ensino público na educação básica, de acordo com as suas peculiaridades e conforme os princípios da participação dos profissionais da educação na elaboração do projeto pedagógico da escola; e da participação das comunidades escolar e local em conselhos escolares ou equivalentes.

Como definido no Manual Básico da Escola Superior de Guerra, "o poder militar tem suas raízes na força e, quando dela não chega a fazer uso, com ela ameaça pela possibilidade constante de fazê-la presente' (Manual, 1976, p. 375). Naturalmente, o exercício da força pelo efetivo militar, característico do próprio Estado moderno - o exercício legítimo da força, na conhecida formulação do contratualismo moderno -, pressupõe a existência de uma instituição coesa e hierarquicamente organizada sob o signo da disciplina. Por isso hierarquia e disciplina estão no DNA de toda e qualquer instituição militar, mesmo as instituições de ensino militar, o que se choca com os princípios constitucionais acima destacados, cujo eixo é o valor liberdade.

Em se tratando de organizações militares, embora com escopos educacionais, os colégios militares adotam um alinhamento político-pedagógico que tem como eixo a doutrina militar, ou seja, um conjunto de princípios e processos teóricos concebidos para "atender aos problemas militares de uma nação ou coligação, para organizar suas forças, prepará-las para a guerra e conduzilas nas operações admitidas e previstas" (Manual, 1976, p. 381).

A doutrina militar está contida na doutrina de guerra e ambas atendem aos conceitos da doutrina de segurança nacional levada a cabo no período de ditadura civil-militar no Brasil, sobretudo por intermédio da edição do AI-5. Referida doutrina foi cuidadosamente elaborada no âmbito da Escola Superior de Guerra, em colaboração com o Instituto de Pesquisas e Estudos Sociais (IPES) e o Instituto Brasileiro de Ação Democrática (IBAD), durante os anos que antecederam o golpe e está baseada, dentre outros elementos, numa teoria da guerra - e seus diferentes tipos (guerra total, guerra limitada e localizada; guerra

20 Art. 206. O ensino será ministrado com base nos seguintes princípios: (...) II - liberdade de aprender, ensinar, pesquisar e divulgar o pensamento, a arte e o saber; III - pluralismo de ideias e de concepções pedagógicas, e coexistência de instituições públicas e privadas de ensino; (...) VI - gestão democrática do ensino público, na forma da lei". 
subversiva ou revolucionária; guerra indireta ou psicológica) - em que a segurança interna tem grande destaque e se equipara aos reclamos de garantia contra ataques externos. ${ }^{21}$ Durante a regime ditatorial de 64, o Estado de Segurança Nacional encontrava justificação para o controle e a repressão da população como um todo (Cf. ALVES, 1987), transformada em inimiga potencial, o que punha em xeque a defesa dos direitos humanos e todas as garantias de exercício de direitos políticos. A Doutrina da Segurança Nacional funda-se também num forte viés econômico, cuidando-se da adoção de um modelo liberal, mas com forte e decisiva presença do Estado, no qual o desenvolvimento econômico não está voltado para as necessidades fundamentais, ou seja, “(...) a política de desenvolvimento não se preocupa muito com o estabelecimento de prioridades para a rápida melhoria dos padrões de vida da maioria da população" (ALVES, 1987, p. 51).

O resgate de tais elementos históricos é fundamental e nos permite compreender porque no Estado do Rio de Janeiro os cargos de direção, magistério e administração são preenchidos, exclusivamente, por elementos dos quadros da Polícia Militar, sendo o cargo de direção privativo de Oficial de nível superior, o que viola o art. 206, V, da Constituição Federal ${ }^{22}$ e também o art. 15 da LDB, os quais, respectivamente, asseguram progressivos graus de autonomia pedagógica e administrativa às unidades escolares públicas de educação básica. ${ }^{23}$

\section{O PRINCÍPIO CONSTITUCIONAL DA IGUALDADE E DO ACESSO IGUALITÁRIO À EDUCAÇÃO}

Além das incompatibilidades com o texto constitucional e com a legislação educacional acima apontadas, é preciso reconhecer que a preferência ou reserva de vagas conferida aos dependentes e órfãos da Polícia Militar e do Corpo de Bombeiros Militar no processo de ingresso aos CPMERJ e CCBM, com possibilidade de atendimento à sociedade em geral apenas na existência de vagas ociosas remanescentes, viola o princípio constitucional de igualdade e do acesso igualitário à educação.

\footnotetext{
21 De acordo com a ESG, Segurança Nacional "É o grau de garantia que - através de ações Políticas, Econômicas, Psicossociais e Militares - o Estado proporciona, em determinada época, à Nação que jurisdiciona para a conquista ou manutenção dos Objetivos Nacionais, a despeito dos antagonismos ou pressões existentes ou potenciais” (MANUAL, 1976, pp. 418-419).

22 Art. 206. O ensino será ministrado com base nos seguintes princípios: (...) V - valorização dos profissionais da educação escolar, garantidos, na forma da lei, planos de carreira, com ingresso exclusivamente por concurso público de provas e títulos, aos das redes públicas”.

23 Art. 15. Os sistemas de ensino assegurarão às unidades escolares públicas de educação básica que os integram progressivos graus de autonomia pedagógica e administrativa e de gestão financeira, observadas as normas gerais de direito financeiro público.
} 
Neste ponto, merecem destaque os números do quadro abaixo que refletem o resultado do processo seletivo para ingresso de novos alunos no I CPMERJ (Niterói) e II CPMERJ (Campo Grande) para o ano letivo de 2020, tornado público pela PMERJ ${ }^{24}$, e que deixam evidente o desequilíbrio do atendimento tendo por consideração a origem dos candidatos aprovados e classificados.

\begin{tabular}{|c|c|c|c|c|}
\hline \multirow{2}{*}{$\begin{array}{c}\text { Unidade/ Ano de Ingressol } \\
\text { Origem dos Candidatos }\end{array}$} & \multicolumn{2}{|c|}{ I CPMERJ } & \multicolumn{2}{c|}{ II CMPERJ } \\
\cline { 2 - 5 } & $6^{0}$ Ano EF & $1^{0}$ Ano EM & $6^{0}$ Ano EF & $1^{0}$ Ano EM \\
\hline Dependentes de Policial Militar & 13 & 17 & 26 & -- \\
\hline $\begin{array}{c}\text { Dependentes de órfãos de } \\
\text { Policial Militar }\end{array}$ & 07 & 08 & 13 & - \\
\hline $\begin{array}{c}\text { Não Dependentes (Público } \\
\text { Externo) }\end{array}$ & 02 & 03 & 04 & - \\
\hline Total de Vagas & 22 & 28 & 43 & - \\
\hline
\end{tabular}

Fonte. Elaborado pelos autores.

No quadro acima é perceptível uma clara restrição de acesso aos CPMERJ, uma vez que o quantitativo de alunos aprovados dentre o denominado "público externo" é de cerca de apenas 10\% (dez por cento) do total de vagas em cada uma das unidades escolares analisadas.

É também relevante ressaltar que os editais de seleção para o processo de matrícula para o ano letivo de 2019, relativos aos II CPMERJ (Campo Grande) e III CPMERJ (Duque de Caxias), sequer previam a existência de vagas para o "público externo", a demonstrar que a previsão do número de vagas e sua distribuição são atos arbitrários do Comando Geral da Polícia Militar, sem qualquer controle social.

Como não se ignora, o texto constitucional brasileiro estabelece a igualdade de todos perante a lei, cuidando-se de um dos mais elementares direitos fundamentais, individual e coletivamente considerado. ${ }^{25}$ Além da cláusula geral de igualdade, o texto constitucional de 1988 estabelece que a educação é um direito de todos e dever do Estado e da família (art. 205) e que o ensino será ministrado com base, dentre outros, no princípio de igualdade de condições para o acesso e permanência na escola (art. 206, I). Cuida-se, também aqui, de um direito fundamental.

24 Em https://cpm.pmerj.rj.gov.br/wp-content/uploads/2019/10/Site-CPM-

Rela $\% \mathrm{C} 3 \% \mathrm{~A} 7 \% \mathrm{C} 3 \% \mathrm{~A} 30-$ de-Candidatos-por-pontua $\% \mathrm{C} 3 \% \mathrm{~A} 7 \% \mathrm{C} 3 \% \mathrm{~A} 3 \mathrm{o}$.pdf

25 "Art. $5^{\circ}$. Todos são iguais perante a lei, sem distinção de qualquer natureza, garantindo-se aos brasileiros e aos estrangeiros residentes no País a inviolabilidade do direito à vida, à liberdade, à igualdade, à segurança e à propriedade, nos termos seguintes: I - homens e mulheres são iguais em direitos e obrigações, nos termos desta Constituição". 
No mesmo sentido dispõe a LDB, cujo art. $3^{\circ}$, I, não deixa qualquer dúvida sobre o acesso igualitário à educação, ${ }^{26}$ e também a Lei 8.069/1990 (ECA), cujo art. 53 garante a igualdade de condições para o acesso e permanência na escola.

É certo que o princípio da igualdade, em sua dimensão material, pressupõe o "tratamento desigual aos desiguais", isto é, que as diferenças de fato sejam também levadas em conta pelo legislador no seu preciso dimensionamento. Ou seja, a exata compreensão da igualdade jurídica conduz a que se tratem os desiguais de forma desigual, na exata medida de sua desigualação. Em razão disso, a jurisprudência do Supremo Tribunal Federal tem por constitucional a política de cotas na educação superior (por exemplo, ADPF 186, Rel. Min. Ricardo Lewandowski, j. 26.04.12), que reconhece a histórica situação de desigualdade política, social e econômica da população negra em nosso país, que tem a escravidão como causa.

Especificamente sobre as denominadas "ações afirmativas" ou "discriminações positivas" e suas correlações com o princípio constitucional da igualdade, merece destaque o pioneiro trabalho de Rocha, que inicia as suas reflexões indagando sobre se a igualdade é um direito assegurado de modo eficiente pelo sistema constitucional pela sua mera previsão formal no rol dos direitos fundamentais, no qual se proíbe a manifestação de qualquer preconceito e discriminação, e se seria suficiente ao Direito Constitucional "assegurar formalmente a igualdade (...) ou volta-se ele à concepção de instrumentos pelo quais se promova a igualação jurídica e, dessa forma, aperfeiçoar-se o princípio da isonomia", para responder negativamente à primeira e afirmativamente à segunda indagação, e concluir pela plena compatibilidade entre as ações afirmativas e as regras constitucionais (ROCHA, 1996, pp. 283 e ss.).

O sistema legislativo brasileiro, como de resto os sistemas jurídicos dos Países ocidentais, é pródigo em prever mecanismos proibitivos de condutas discriminatórias de toda espécie (origem, raça, credo etc), servindo-se de uma série de normas de cunho sancionatório, penais ou administrativas, como por exemplo as previstas na Lei n. 7.716/89, que define os crimes resultantes de preconceito de raça ou cor.

Tem-se como incontroversa nos dias atuais, não obstante, a insuficiência da adoção de mecanismos legais meramente proibitivos de práticas discriminatórias, ou mesmo a pura e simples enunciação, ainda que constitucional, do princípio da

26 Art. $3^{\circ} \mathrm{O}$ ensino será ministrado com base nos seguintes princípios: I - igualdade de condições para o acesso e permanência na escola; (...). 
igualdade, incapazes que são tais instrumentos de, realisticamente, produzirem e alcançarem a igualitária fruição dos direitos fundamentais, tais como o direito à vida e à saúde, ao emprego, à instrução etc.

Em tal perspectiva é que surgem as chamadas "ações afirmativas", estratégia jurídica de superação do isolamento ou o desprestígio social das minorias (ROCHA, 1996), um conjunto de políticas públicas, compulsórias ou não, voltadas ao combate à discriminação racial, de gênero e de origem nacional e à correção dos efeitos históricos causados às minorias com vistas à concretização da igualdade e do acesso a direitos fundamentais (GOMES, 2001).

Representam as ações afirmativas a adoção de uma postura nova e essencialmente ativa por parte do Estado, que, no momento de contratar seus funcionários ou de regular o ingresso ao ensino superior, por exemplo, passa a ter em conta, a partir de uma desigualação historicamente demonstrável, os fatores sexo, raça e cor. Assim, o Estado considera a valoriza tais fatores no desenho da política pública a fim de fazer cessar desigualdades sociais, indo além das categorias jurídicas clássicas (GOMES, 2001).

Não é o caso, contudo, da reserva de vagas para dependentes ou órfãos de policiais e bombeiros militares, a respeito dos quais não há qualquer justificativa histórica a fundamentar um tratamento diferenciado. E na ausência dessa justificativa histórica, o tratamento desigual e mais favorável que recebem em relação ao acesso aos colégios militares estaduais não pode ser considerado isonômico, mas, ao contrário, representa a concessão de um privilégio indevido e, portanto, insustentável diante da ordem jurídica constitucional.

Não vai aqui, naturalmente, qualquer demérito aos Policiais ou Bombeiros Militares, que prestam serviços essenciais à sociedade e que não são devidamente valorizados pelo Poder Público, sobretudo na perspectiva remuneratória. Contudo, a ser este um fundamento suficiente à instituição de reservas de vagas em escolas ou em quaisquer outros serviços públicos, teríamos também que admitir o mesmo tratamento a filhos de Guardas Municipais, Agentes Penitenciários, Inspetores de Polícia etc - e igualmente a profissionais das áreas de saúde e educação, que também prestam serviços essenciais à sociedade-, em clara violação ao texto constitucional.

Sobre o desafio da superação das desigualdades existentes no Brasil, Henriques (2009) pontua a importância da desigualdade educacional e da desigualdade racial, parâmetros que devem informar a redefinição dos paradigmas educacionais e uma nova agenda de políticas públicas que seja capaz de enfrentar as dívidas que o país tem com as populações vulneráveis, em especial com as populações negra e indígena e com os povos do campo. 
E essa nova agenda no plano educacional deve passar, de um lado, pela eliminação de todas as formas de privilégio em relação ao acesso, à permanência, à participação ou à aprendizagem na escola pública e, de outro, pela adoção progressiva de ações afirmativas educacionais que sejam capazes de reorganizar ou remodelar os sistemas de ensino como um todo (Ibidem, p. 8-9), e não apenas em benefício dos interesses burocráticos do Estado e de alguns de seus servidores, tampouco de interesses autoritários.

\section{CONSIDERAÇÕES FINAIS}

No atual cenário da educação pública no Rio de Janeiro, em que o descumprimento sistemático das obrigações em matéria educacional é frequentemente atribuída à escassez orçamentária e financeira, não se justifica a intenção manifesta dos Poderes Executivo e Legislativo em ampliar a oferta do ensino militar por meio da instalação de novos colégios militares da PMERJ e do CBMERJ.

E isto, como se disse, por três razões essenciais. Primeiro, porque a prestação do serviço educacional por corporações militares representa uma ampliação inconstitucional da esfera de suas atribuições próprias. Segundo, porque os princípios que orientam a atuação das polícias militares e dos corpos de bombeiros militares (hierarquia e disciplina) não se coadunam com aqueles que informam a oferta da educação escolar no Brasil, atravessados pela liberdade como valor e ancorados no Estado Democrático. Finalmente, porque embora essas unidades de ensino sejam financiadas com recursos públicos alegadamente escassos, por vezes em volume per capita superior ao observado na generalidade das demais escolas públicas, promovem reserva injustificada de vagas para dependentes e órfãos de tais corporações, em detrimento do atendimento da população em geral, em violação frontal e insuperável aos princípios constitucionais da igualdade e do acesso igualitário à educação, com o que contribuem para o aprofundamento das desigualdades educacionais que marcam a sociedade brasileira e fluminense.

\section{REFERÊNCIAS}

ALVES, Maria Helena Moreira. Estado e Oposição no Brasil (1964-1984). 4 ed. Petrópolis: Vozes, 1987.

ARGUELHES, Diego Werneck \& LEAL, Fernando. O Argumento das "capacidades institucionais" entre a banalidade, a redundância e o absurdo. In Direito, Estado e Sociedade, n. 38, jan/jun de 2011, pp. 6-50. 
BRASIL. Constituição da República Federativa do Brasil. Brasília, DF: Senado Federal, 1988.

Lei Federal $\mathrm{n}^{\circ}$ 9.394, de 20 de dezembro de 1996, estabelece as diretrizes e bases da educação nacional.

Lei Federal n $^{\circ}$ 9.786, de 08 de fevereiro de 1999, dispõe sobre o Ensino no Exército Brasileiro e dá outras providências.

Decreto Estadual n $\mathbf{n}^{\mathbf{3}}$ 3.182, de 23 de setembro de 1999, regulamenta a Lei no 9.786 , de 8 de fevereiro de 1999, que dispõe sobre o ensino no Exército Brasileiro. do Exército.

Portaria $^{\circ}$ 42, de 06 de fevereiro de 2008, expedida pelo Comando GOMES, Joaquim B. Barbosa. Ação afirmativa e princípio constitucional da igualdade. Rio de Janeiro: Renovar, 2001.

HENRIQUES, Ricardo. Apresentação. In Ações Afirmativas nas Políticas Educacionais: o contexto pós-Durban. São Carlos: EduFSCar, 2009, p. 7-10.

Manual Básico da Escola Superior de Guerra. Rio de Janeiro: Estado-Maior das Forças Armadas (Escola Superior de Guerra, Departamento de Estudos), 1976.

RIO DE JANEIRO. Constituição do Estado do Rio de Janeiro. Rio de Janeiro, RJ: Assembleia Legislativa, 1989.

Decreto Estadual n ${ }^{\mathbf{1}}$ 15.427, de 04 de setembro de 1990, transforma a Diretoria Geral de Ensino em Diretoria de Ensino e Instrução da Polícia Militar do Estado do Rio de Janeiro e aprova o seu regulamento.

Lei Estadual $\mathrm{n}^{\circ}$ 3751, 07 de maio de 2002, autoriza o Poder Executivo a criar o Colégio da Polícia Militar - CPM.

Lei Estadual $\mathrm{n}^{\circ}$ 4.133, de 12 de agosto de 2003, autoriza o Poder Executivo a criar o colégio do Corpo de Bombeiros Militar - CCBM. 
Portaria $\mathrm{n}^{\mathbf{0}} \mathbf{6 0 8}$, de 01 de junho de 2010, aprova o regulamento da Diretoria Geral de Ensino e Instrução do Corpo De Bombeiros Militar do estado do Rio de Janeiro.

.Lei Estadual $n^{\circ}$ 6343, de 21 de novembro de 2012, altera a Lei ${ }^{\circ}$ 3751, de 07 de janeiro de 2002, que "autoriza o poder executivo a criar o Colégio Da Polícia Militar - CPM"'.

.Lei Estadual n ${ }^{\circ}$ 8198, de 07 de dezembro de 2018, autoriza o Poder Executivo a criar outras 3 (três) novas unidades do Colégio da Polícia Militar.

.Decreto $\mathrm{n}^{\circ}$ 22, de 10 de setembro de 2018, cria o III Colégio Militar no Município de Duque de Caxias.

.Decreto Conjunto $\mathrm{n}^{\mathrm{o}} 02$ de 14 de novembro de 2018, ratifica o Decreto $^{\circ}$ 22, de 10 de setembro de 2018, publicado no D.O. de 11/09/2018.

.Decreto Estadual $\mathrm{n}^{\circ} 46.592$ de 28 de fevereiro de 2019, dispõe sobre a criação de colégios do Corpo de Bombeiros Militar do Estado Do Rio De Janeiro na forma que menciona, e dá outras providências.

.Lei $\mathrm{n}^{\circ} \mathbf{8 4 5 0}$, de 05 de julho de 2019, autoriza o Poder Executivo a implantar um colégio militar no município de Queimados.

.Projeto de Lei $\mathbf{n}^{\circ}$ 192/2019 autoriza a criação de colégios militares por transformação das unidades escolares estaduais atualmente localizadas em todas as comunidades do Estado do Rio de Janeiro.

Projeto de Lei $\mathrm{n}^{\circ} 862 / 2019$, autoriza o Estado do Rio de Janeiro a realizar convênio com os Municípios para a criação de escolas militares municipais.

ROCHA, Carmen Lúcia Antunes. Ação afirmativa: o conteúdo democrático do princípio da igualdade jurídica. In Revista Trimestral de Direito Público, n. 15, p. 85-99, 1996.

TÁCITO, Caio. Temas de Direito Público: estudos e pareceres. Rio de Janeiro: Renovar, 1997. 
XIMENES, Salomão Barros; STUCHI, Carolina Gabas; MOREIRA, Márcio Alan Menezes. A militarização das escolas públicas sob o enfoque de três direitos: constitucional, educacional e administrativo. In Revista Brasileira de Política e Administração da Educação (RBPAE) - v. 35, n. 3, p. 612 - 632, set./ dez. 2019.

\section{Rogério Pacheco Alves}

Doutor em Direito Constitucional e Teoria do Estado pela PUC-Rio. Professor adjunto da Universidade Federal Fluminense. Promotor de Justiça do Ministério Público no Estado do Rio de Janeiro. E-mail: rogeriopachecoalves@id.uff.br

\section{Debora da Silva Vicente}

Doutoranda e Mestre em Educação pelo Programa de Pós-Graduação em Educação da Universidade Federal Fluminense (PPGE-UFF). Especialista em Administração Pública pela Fundação Getúlio Vargas (FGV). Promotora de Justiça do Ministério Público do Estado do Rio de Janeiro. E-mail: debora@ mprj.mp.br 